\title{
An unusual case of atlanto-axial and basi-occipital TB with prevertebral abscess and epidural abscess
}

\author{
Sameer Mansukhani, Manit Arora*, Sachin Kale and Sanjay Dhar \\ *Correspondence: manit_arora@hotmail.com

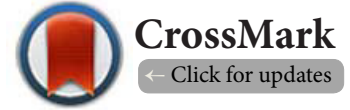

Department of Orthopaedics, Padhamshree Dr. DY Patil Hospital and Research Centre, Navi Mumbai, India.

\begin{abstract}
TB is a re-emerging disease worldwide, affecting about one-third of the world's population, and second only to HIV/AIDS as the greatest killer worldwide. Skeletal TB constitutes 3-5\% of all cases of TB, with cervical spine TB making up only $2-3 \%$ of cases of TB spine. Tuberculosis of the cranio-cervical junction is rare and accounts for only about $1 \%$ of all cases of spinal TB. Co-existence with pre or paravertebral abscess is rarer. We present a case of atlanto-axial and basi-occipital TB with a large paravertebral abscess and anterior epidural abscess without any neurological symptoms. To our knowledge this is the first such reported case in the literature. The patient was managed non-operatively using the middle path regimen with significant improvement in symptoms.
\end{abstract}

Keywords: Tuberculosis, spine, cervical, atlanto-axial, anti-tuberculosis theraoy, abscess, basi-occipital

\section{Introduction}

Tuberculosis (TB) is a re-emerging disease worldwide, affecting about one-third of the world's population, and second only to HIV/AIDS as the greatest killer worldwide [1]. In 2012, 8.6 million people world-wide fell ill with TB and 1.3 million died from TB, with over $95 \%$ of deaths occurring in low- and middleincome countries [1]. Skeletal TB constitutes 3-5\% of all cases of TB, with TB of the spine being the most common form of musculoskeletal TB [2]. Cervical spine TB is rare, constituting $2-3 \%$ of cases of TB spine [3]. Cranio-cervical TB accounts for only about $1 \%$ of all cases of spinal TB [4]. Co-existence with prevertebral abscess is rarer, with only a handful of cases reported in the literature [5-14].

Cranio-cervical TB carries the significant risk of neurological involvement [15] and hence recognition and intervention are critical. The following is a case report of an unusual case of atlanto-axial and basi-occipital TB with a prevertebral abscess and an anterior epidural abscess without any neurological symptoms. To our knowledge, this is the first such reported case in the literature.

\section{Case report}

A 19 year old manual labourer and part-time student presented to our institution with a one year history of upper and lower neck pain, decreased and painful range of motion of the neck, left postero-lateral neck swelling, toricollis and constitutional symptoms (fever, night sweats and weight loss).

The patient had a one year history of upper and lower neck pain which was continuous and dull aching in nature, with bilateral radiation into the upper limbs and axilla. The pain was aggravated with activity, persistent with rest and unrelieved by analgesia. The patient also have a one year history of night cries and constitutional symptoms such as evening rise of temperature, night sweats, five kilograms of weight loss and anorexia. Three months ago the patient started complaining of a localized neck swelling without any associated respiratory symptoms or difficulty in swallowing. The patient gave a positive history of close contact of family member with TB two years ago and having unprotected sexual intercourse.

The patient gave a negative history of parasthesia or weakness to the upper or lower limbs, parasthesias or radiation of pain to the lower back and the lower limbs, a past history of Koch's disease or treatment for the same, and dyspnea, headaches, vertigo, pre-syncopal episodes, chest pain or other cardiovascular symptoms. The patient denied smoking, alcohol or recreational drug use, or close contact with HIV carriers. The patient was from a low socio-economic background and lived in slum-like conditions, sharing his room with five other students.

On physical examination, the patient had aleft sided torticollis and amoderate size localised tender swelling to the poster- 
olateral aspect of the lower neck on the left hand side, with characteristic features of a cold abscess. The $\mathrm{C} 2, \mathrm{C} 3, \mathrm{C} 4$ and C5 vertebrae were tender to superficial and deep palpation. The range of motion of the neck was restricted and painful for lateral rotation bilaterally, but otherwise normal. There was no midline tenderness to the lower dorsal or lumbar regions, and no paraspinal muscle spasm to the same. Hip examination was normal bilaterally. Neurovascularly, the patient was intact. The patient did not exhibit features of either lower or upper motor neuron involvement, or higher centre involvement.

The laboratory investigations for the patient revealed a microcytic hypochromic anaemia $(\mathrm{Hb}-11.7 \mathrm{~g} / \mathrm{dL})$. The patient had a low WBC count (4500 cells/uL), low RBC count (3100000 cells/uL) and a low platelet count ( 90000 cells/uL).

Iron studies showed a low serum iron $(26.2 \mathrm{ug} / \mathrm{dL})$ and low serum ferritin $(10.30 \mathrm{ng} / \mathrm{mL})$. The ESR was elevated $(87 \mathrm{~mm} /$ $\mathrm{hr}$ ) as was the C-reactive protein (53.42). Serum electrolytes, renal function tests and liver function tests were essentially normal. HIV, Hepatitis C and Hepatitis B tests were negative. ECG was normal and echocardiogram revealed a normal left ventricular cavity size, normal other chambers, normal valves and a left ventricular ejection fraction of $75 \%$. Chest radiograph was unremarkable with no evidence of active or healed tuberculosis disease.

Radiography (Figure 1), CT imaging (erosion of the anterior and left anterior arch of $\mathrm{C} 1$ vertebra and basi-occipital region, large peripherally enhancing collection in the left paravertebral and retropharyngeal region extending from $\mathrm{C} 1$ to $\mathrm{C} 4$, small peripherally enhancing collection in right pre-vertebral region of C1 to C2, and enlarged lymph nodes at level II, III, IV and V on the left side of neck) and MR imaging (Figure 2) confirmed our clinical suspicion of antanto-axial and basi-occipital TB with cold abscess.

The patient has completed an anti-TB regimen of 2 months of isoniazid, rifampicin, pyrazinamide and streptomycin, with adjunct of pyridoxine, and is currently on stage 2 of the WHO TB regimen. Supportive measures such as analgesia, cervical traction with $4 \mathrm{~kg}$ of weight with the neck extended when recumbent, and Philadelphia collar when non-recumbent, were also initiated. The patient had significant pain relief. Repeat ESR $(57 \mathrm{~mm} / \mathrm{hr})$ and CRP $(<0.50)$ values were reduced. We expect consolidation of paravertebral abscess with current regimen on anti-tuberculosis therapy which will be continued for at least 4 months more.

\section{Discussion}

TB is a re-emerging disease worldwide, affecting about onethird of the world's population, and second only to HIV/AIDS as the greatest killer worldwide.

Cervical spine TB is rare, constituting 2-3\% of cases of TB spine [3]. TB of the cranio-cervical junction is even more rare, constituting $1 \%$ of all spinal TB cases [4]. Co-existence with prevertebral abscess is rarer, with only a handful of cases reported in the literature [5-14]. TB of the cranio-cervical
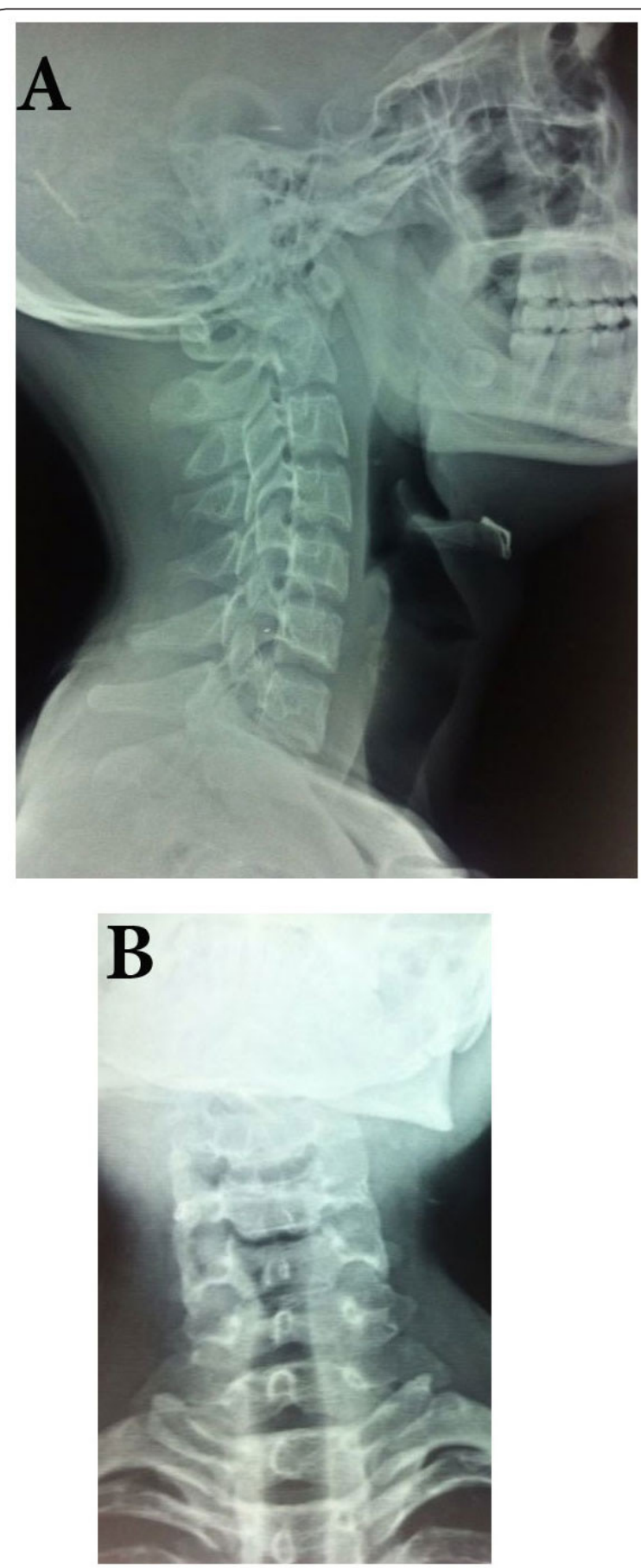

Figure 1. Anteroposterior and lateral radiographs of the cervical spine showing destruction of the atlanto-axial articulation with widening of the dens-basilar interval and the atlanto-dens interval.

junction probably begins as an infection in the retropharyngeal space with subsequent infection of surrounding vertebral structures. Progression of the disease causes increasing ligamentous involvement, with later stages characterized by destruction of bone [16]. 


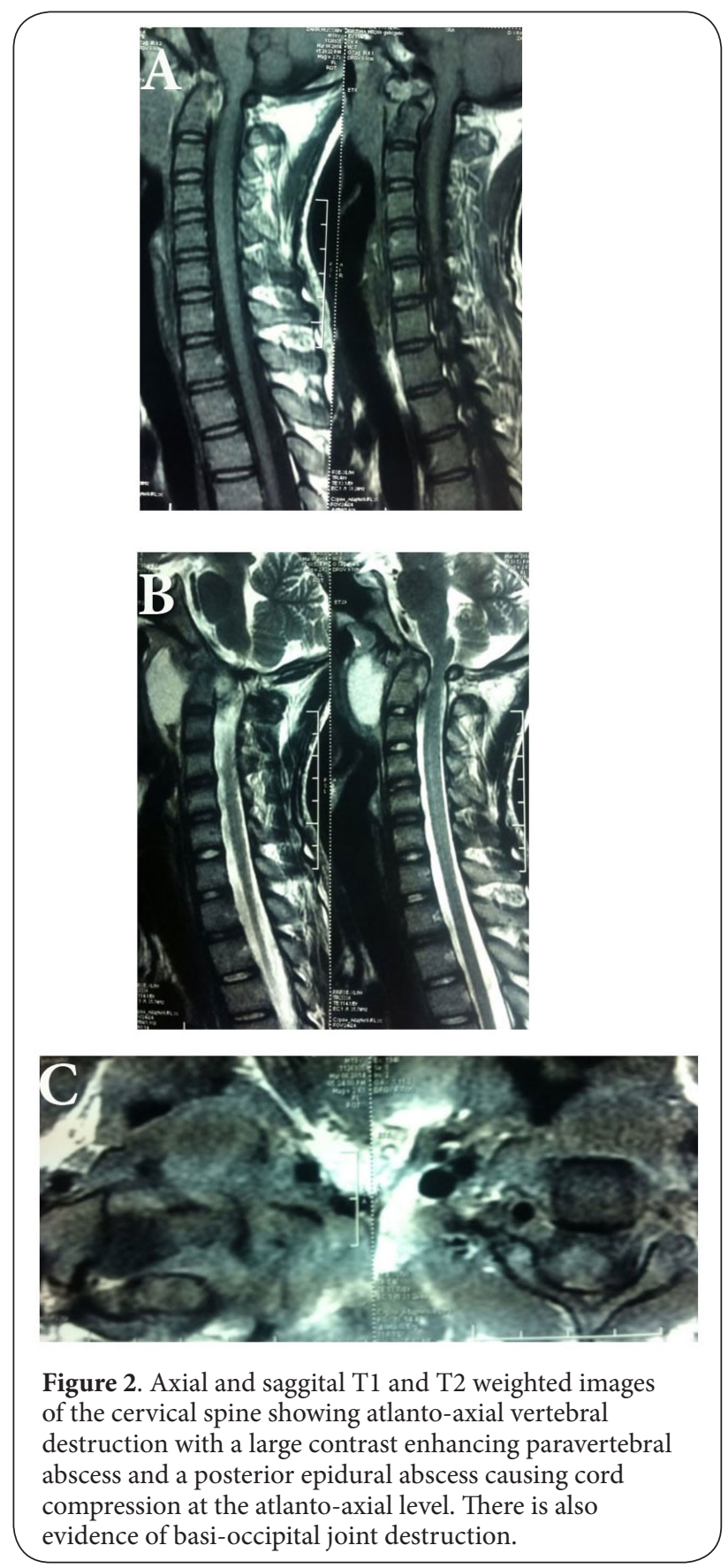

In his review of 12 cases of adult atlanto-axial TB, Lifeso (1987) proposed a classification system: stage I has minimal ligamentous or bone destruction and no displacement of C1 on C2; stage II has ligamentous disruption and minimal bone destruction but anterior displacement of $\mathrm{C} 1$ on $\mathrm{C}_{2}$; and, stage III has marked ligamentous and bone destruction with displacement of $\mathrm{C} 1$ forward on $\mathrm{C2}$ [16]. The radiographic and MR images of our case are consistent with Lifeso Stage III disease. Of note, the C1-C2 subluxation was not recognized on MR imaging in our case due to the neck position, and so flexion and extension views on a standard lateral radiograph are necessary in such cases to prevent the diagnosis being overlooked.

TB spine carries a significant risk of neurological involvement [15]. Figures in the literature suggest neurological involvement in 24 to $64 \%$ of cases of cervico-cranial TB with quadraparesis being the most common outcome [15]. Our case had significant anterior epidural abscess with MRI signs of cord compression, however the patient was neurological intact, suggesting that MRI changes not be foregone for clinical assessment. Early diagnosis and prompt treatment is necessary to prevent neurological disability and to minimize spinal deformity [17]. Accordingly, we instituted cervical traction and anti-tuberculosis regimen.

The cornerstone of management of spinal TB is prompt initiation of anti-TB treatment. Almost all anti-TB drugs penetrate well into the vertebral lesions.

Various studies have shown that the majority of patients (82-95\%) with spinal TB respond very well to medical treatment in terms of pain relief, decrease in neurological deficit, and even correction of spinal deformity $[16,18,19]$. Treatment is divided into two phases: an intensive (initial) phase and a continuation phase, according to WHO guidelines [1]. The intensive phase consists of a 2 month course of four-first line drugs: isoniazid, rifampicin, streptomycin and pyrazinamide. In the continuation phase, isoniazid and rifampicin are given for 4 months. WHO recommends 9 months of treatment for tuberculosis of bones or joints [20], whereas the American Thoracic Society recommends 6 months for spinal TB in adults and 12 months for children [21]. The British Thoracic Society recommends 6 months of daily treatment with rifampicin and isoniazid, supplemented in initial 2 months with pyrazinamide and either ethambutol or streptomycin [22]. We followed the WHO guidelines to guide our treatment regimen in this particular case. However, in contrast to the ambulatory care guidelines of $\mathrm{WHO}$, we used cervical traction $(4 \mathrm{~kg})$ with neck extended in recumbent position and a Philadelphia collar in the non-recumbent position to provide symptomatic relief, maintain spinal stability and prevent progression of deformity.

The role of surgery in TB spine is controversial. A Cochrane Database Review assessing the role of routine surgery, as advocated by Hodgson and Stock in 1960 [23], in addition to chemotherapy concluded that evidence was insufficient for the routine use of surgery. There were no statistically significant differences for any of the outcome measures: kyphosis angle, neurological deficit, bony fusion, absence of spinal TB, death from any cause, activity level regained, change of allocated treatment, or bone loss [18]. Of note, the Cochrane Review only included 2 randomized control trials with a total of 331 participants and it is difficult to draw broad conclusions based on such small sample size. Tuli, in 1975, proposed a'middle-path' regimen for treatment of spinal TB consisting of conservative treatment with multi-drug chemotherapy and surgery reserved for specific indications [24]. Sell had recommended lack of clinical improvement as an indication for surgery, along with 
Mansukhani et al. Journal of Rheumatology and Orthopedics 2014,

http://www.hoajonline.com/journals/pdf/2055-7000-1-4.pdf

doi: $10.7243 / 2055-7000-1-4$

pan-vertebral lesions and refractory disease [25]. We followed Tuli's middle-path regimen in our particular case.

\section{Conclusion}

We present a rare case of basi-occipital and atlanto-axial TB with large paravertebral abscess and anterior epidural abscess without neurological involvement in a young male. The patient was managed non-operatively with significant improvement in symptoms and reduction in size of abscess.

\section{Competing interests}

The authors declare that they have no competing interests.

\section{Authors' contributions}

\begin{tabular}{|l|l|l|l|l|}
\hline Authors' contributions & SM & MA & SK & SD \\
\hline Research concept and design & $\checkmark$ & $\checkmark$ & $\checkmark$ & $\checkmark$ \\
\hline Collection and/or assembly of data & $\checkmark$ & $\checkmark$ & -- & -- \\
\hline Data analysis and interpretation & -- & -- & $\checkmark$ & $\checkmark$ \\
\hline Writing the article & $\checkmark$ & $\checkmark$ & -- & -- \\
\hline Critical revision of the article & -- & -- & $\checkmark$ & -- \\
\hline Final approval of article & -- & -- & -- & $\checkmark$ \\
\hline Statistical analysis & -- & -- & -- & -- \\
\hline
\end{tabular}

Publication history

Editor: Bruce M Rothschild, Northeast Ohio Medical University, USA. Received: 23-Apr-2014 Final Revised: 01-Aug-2014

Accepted: 02-Aug-2014 Published: 22-Aug-2014

\section{References}

1. Tuberculosis. WHO. 2014. | Website

2. Fang $D$, Leong JC and Fang HS. Tuberculosis of the upper cervical spine. $J$ Bone Joint Surg Br. 1983; 65:47-50. | Article | PubMed

3. Lukhele M. Tuberculosis of the cervical spine. S Afr Med J. 1996; 86:5536. | Article | PubMed

4. Kanaan IU, Ellis M, Safi T, Al Kawi MZ and Coates R. Craniocervical junction tuberculosis: a rare but dangerous disease. Surg Neurol. 1999; 51:21-5. | Article | PubMed

5. Agada FO, Sharma R and Makura ZG. Atypical presentation of cutaneous tuberculosis and a retropharyngeal neck abscess. Ear Nose Throat J. 2006; 85:60-2. | Article | PubMed

6. Al Soub H. Retropharyngeal abscess associated with tuberculosis of the cervical spine. Tuber Lung Dis. 1996; 77:563-5. | Article | PubMed

7. Ogah $O$, Owolabi $M$ and Akisanya $C$. Cervical spine tuberculosis and retropharyngeal abscess in an adult Nigerian. Ann Trop Med Public Heal. 2012; 5:587. | Article

8. Attia M, Harnof S, Knoller N, Shacked I, Zibly Z, Bedrin L and Regev-Yochay G. Cervical Pott's disease presenting as a retropharyngeal abscess. Isr Med Assoc J. 2004; 6:438-9. | Pdf | PubMed

9. Bhargava SK and Gupta S. Large retropharyngeal cold abscess in an adult with respiratory distress. J Laryngol Otol. 1990; 104:157-8. | Article | PubMed

10. Carroll N, Bain RJ, Tseung MH and Edwards RH. Tuberculous retropharyngeal abscess producing respiratory obstruction. Thorax. 1989; 44:599-600. | Article | PubMed Abstract | PubMed Full Text

11. de Clercq LD and Chole RA. Retropharyngeal abscess in the adult. Otolaryngol Head Neck Surg (1979). 1980; 88:684-9. | Article | PubMed

12. Fageeh NA and Lamothe A. Tuberculosis of the retropharyngeal space. $J$ Otolaryngol. 1998; 27:43-5. | Article | PubMed
13. Laretus VF. [Retropharyngeal lymph nodes tuberculous adenitis in adult masked as retropharyngeal abscess ]. Vestn Otorinolaringol. 2000; 34-5. I PubMed

14. Neumann JL and Schlueter DP. Retropharyngeal abscess as the presenting feature of tuberculosis of the cervical spine. Am Rev Respir Dis. 1974; 110:508-11. | PubMed

15. Dhammi IK, Singh S and Jain AK. Hemiplegic/monoplegic presentation of cervical spine (C1-C2) tuberculosis. Eur Spine J. 2001; 10:540-4. | Article | PubMed Abstract | PubMed Full Text

16. Lifeso RM, Weaver $P$ and Harder EH. Tuberculous spondylitis in adults. J Bone Joint Surg Am. 1985; 67:1405-13. | Article | PubMed

17. Jain AK. Tuberculosis of the spine: a fresh look at an old disease. J Bone Joint Surg Br. 2010; 92:905-13. | Article | PubMed

18. Jutte PC and Van Loenhout-Rooyackers JH. Routine surgery in addition to chemotherapy for treating spinal tuberculosis. Cochrane Database Syst Rev. 2006; CD004532. | Article | PubMed

19. Tuli SM. Treatment of neurological complications in tuberculosis of the spine. J Bone Joint Surg Am. 1969; 51:680-92. | Article | PubMed

20. WHO. Treatment of Tuberculosis: guidelines for national programmes. WHO. 2014. I Website

21. Bass JB, Jr., Farer LS, Hopewell PC, O'Brien R, Jacobs RF, Ruben F, Snider $D E$, Jr. and Thornton G. Treatment of tuberculosis and tuberculosis infection in adults and children. American Thoracic Society and The Centers for Disease Control and Prevention. Am J Respir Crit Care Med. 1994; 149:1359-74. | Article | PubMed

22. Chemotherapy and management of tuberculosis in the United Kingdom: recommendations 1998. Joint Tuberculosis Committee of the British Thoracic Society. Thorax. 1998; 53:536-48. | Article | PubMed Abstract | PubMed Full Text

23. Hodgson ARS and Francis E. Anterior Spine Fusion for the Treatment of Tuberculosis of the Spine. J Bone Jt Surg. 1960; 42:295-310. | Article

24. Tuli SM. Results of treatment of spinal tuberculosis by "middle-path" regime. J Bone Joint Surg Br. 1975; 57:13-23. | Article | PubMed

25. Sell P. Expert's comment concerning Grand Rounds case entitled "Posterior listhesis of a lumbar vertebra in spinal tuberculosis" (by Matthew A. Kirkman and Krishnamurthy Sridhar). Eur Spine J. 2011; 20:6-8. | Article | PubMed Abstract | PubMed Full Text

\section{Citation:}

Mansukhani S, Arora M, Kale S and Dhar S. An unusual case of atlanto-axial and basi-occipital TB with prevertebral abscess and epidural abscess. J Rheumatol Orthop. 2014; 1:4. http://dx.doi.org/10.7243/2055-7000-1-4 